PKS

PUBLIC KNOWLEDGE PROJECT

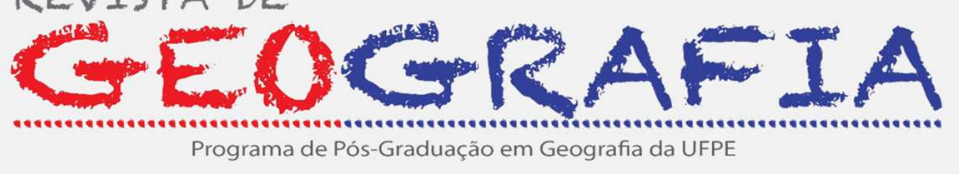

https://periodicos.ufpe.br/revistas/revistageografia
OJS

\title{
TRANSPOSIÇÃO ÀS AVESSAS: EXPORTAÇÃO DE ÁGUA VIRTUAL DO SEMIÁRIDO ATRAVÉS DA BANANICULTURA EMPRESARIAL IRRIGADA DO VALE DO CARIRI CEARENSE*
}

\author{
Paulo Eduardo Rolim Campos ${ }^{1}$, Carlos Wagner Oliveira ${ }^{2}$
}

\begin{abstract}
${ }^{1}$ Geógrafo, doutorando em Agroecologia e Desenvolvimento Territorial na Universidade do Estado da Bahia, Juazeiro, Bahia, Brasil. e-mail: permaculturakariry@gmail.com / https://orcid.org/0000-0002-1978-6811

${ }^{2} \mathrm{PhD}$ em Biosystems Engineering, Professor do Programa de Pós-Graduação em Desenvolvimento Regional Sustentável da Universidade Federal do Cariri, Crato, Ceará, Brasil. e-mail: carlos.oliveira@ufca.edu.br / https://orcid.org/0000-0003-1013-2974
\end{abstract}

*A análise contida nesse artigo é fruto da dissertação: "Exportação de Água Virtual do semiárido e os paradoxos do desenvolvimento: o caso da bananicultura empresarial irrigada no Vale do Cariri cearense", do Programa de PósGraduação em Desenvolvimento Regional Sustentável da Universidade Federal do Cariri (PRODER / UFCA) em 2019.

Artigo recebido em 28/10/2019 e aceito em 27/02/2021

\section{RESUMO}

Zonas urbanas são inseguras do ponto de vista alimentar, pois é priorizado o uso não agrícola da terra, necessitando a importação diária de alimentos, alguns com alta exigência hídrica em sua produção, como a banana (Musa ssp.). O conceito Água Virtual aplica-se ao volume oculto de água em qualquer produção, é necessário conhecer esse volume para melhor gerir os recursos hídricos, ainda mais se a produção é exportada. Analisou-se a capacidade hídrica do Vale do Cariri cearense em suportar a pressão exercida pelas empresas do agronegócio que praticam a bananicultura irrigada. A pesquisa acercou-se do conceito de Água Virtual e partir de imagens de satélite, dados climatológicos e softwares de geoprocessamento, calculou-se o consumo de água nas áreas irrigadas, obtendo o volume de Água Virtual que é exportada a outras regiões do Brasil através da banana, mostrando-se insustentável essa atividade.

Palavras-chave: Água Virtual; Fruticultura Irrigada; Monitoramento Ambiental por Satélite; Segurança Hídrica.

\section{TRANSPOSITION OF THE ADVERSE: EXPORT OF SEMIARID VIRTUAL WATER THROUGH IRRIGATED BUSINESS BANICULTURE OF CARIRI CEARENSE}

\begin{abstract}
Urban areas are insecure from the food point of view, since non-agricultural land use is a priority, necessitating the daily import of food, some with high water requirements in their production, such as bananas (Musa ssp.). The concept Virtual Water applies to the hidden volume of water in any production, it is necessary to know this volume to better manage the water resources, even more if the production is exported. The water capacity of the Cariri Valley was analyzed in order to withstand the pressure exerted by agribusiness companies practicing irrigated banana farming. The research approached the concept of Virtual Water, and from satellite images, climatological data and geoprocessing software, the water consumption in the irrigated areas was calculated, obtaining the volume of Virtual Water that is exported to other regions of Brazil through the banana, showing that this activity is unsustainable.
\end{abstract}


Keywords: Environmental Monitoring by Satellite; Irrigated Fruticulture; Virtual Water; Water Security.

TRANSPOSICIÓN AL REVÉS: EXPORTACIÓN DE AGUA VIRTUAL DEL SEMIÁRIDO A TRAVÉS DE LA BANANICULTURA EMPRESARIAL DE REGADO DEL VALLE DEL CARIRI CEARENSE

\begin{abstract}
RESUMEN
Las zonas urbanas son inseguras desde el punto de vista alimentario, ya que se prioriza el uso no agrícola de la tierra, requiriendo la importación diaria de alimentos, algunos con alta demanda de agua en su producción, como el banana (Musa ssp.). El concepto de Agua Virtual se aplica al volumen oculto de agua en cualquier producción, es necesario conocer este volumen para gestionar mejor los recursos hídricos, especialmente si la producción se exporta. Se analizó la capacidad hídrica de Vale do Cariri en Ceará para resistir la presión que ejercen las empresas agroindustriales que practican el cultivo de banana de regadío. La investigación abordó el concepto de Agua Virtual y con base en imágenes satelitales, datos climatológicos y software de geoprocesamiento, se calculó el consumo de agua en áreas regadas, obteniendo el volumen de Agua Virtual que se exporta a otras regiones de Brasil a través de la banana, demostrando que esta actividad es insostenible.
\end{abstract}

Palabras llave: Água Virtual; Fruticultura de regado; Monitoreo Ambiental por Satélite; Soberanía Hídrica.

\title{
CONSIDERAÇÕES INICIAIS
}

O modelo de urbanização adotado na contemporaneidade tem promovido grandes adensamentos populacionais, segundo Organização das Nações Unidas (ONU) o relatório Perspectivas da Urbanização Mundial (ONU, 2018), 55 \% da população mundial vive em zonas urbanas. Este modelo de assentamento humano é insustentável do ponto de vista da segurança alimentar, fazendo-se necessário a importação diária de grande quantidade de alimento, já que é priorizado o uso não agrícola da terra.

Para a maior parte da população consumidora, a cadeia produtiva dos alimentos é um processo invisível, tal invisibilidade faz com que problemas que resultam da agricultura sejam ocultados, dentre os quais estão os impactos ambientais e a insegurança hídrica da região fornecedora. Uma das problemáticas geradas pela demanda de consumo das zonas urbanas, é que são cultivadas algumas variedades agrícolas que para serem produzidas são altamente exigentes em água.

Exportação de Água Virtual é um termo aplicado ao volume oculto de água contido em um produto que tem como destino um mercado consumidor fora de sua zona de origem. Em regiões com déficit hídrico, conhecer o volume em Água Virtual de um produto pode ser útil para determinar o melhor uso dos recursos hídricos disponíveis. Isso se torna mais relevante se os 
recursos hídricos da região exportadora não forem abundantes, devem-se levar em conta os custos e benefícios obtidos, assim como a água utilizada na produção e calcular se foi realmente lucrativa dada à escassez de água.

Uma análise reflexiva semelhante é a que sugere o caso da bananicultura (cultivo de banana - Musa ssp.) empresarial irrigada no Vale do Cariri cearense. O vale localiza-se ao norte da Chapada do Araripe e embora tenha um clima semiárido brando, tem em seu subsolo um expressivo aquífero, cuja exploração levou a plantação de banana a se tornar a principal atividade econômica agrícola. A produção é destinada ao abastecimento de várias capitais do Nordeste e de outras regiões do país.

Isso parece inadmissível, uma vez que, segundo o Governo do Estado do Ceará, o Vale do Cariri é uma das regiões que já enfrenta estresse hídrico. O município de Missão Velha, maior produtor de banana da região, foi declarado em situação de emergência pelos consecutivos anos de 2010 a 2019 por conta da estiagem (CEARÁ, 2019). Contrapondo-se a essa situação, dados do Instituto Brasileiro de Geografia e Estatística (IBGE), registram no município um aumento de 310 ha para 1777 ha de área colhida com banana no mesmo período (IBGE, 2019), elevando em mais de $470 \%$ a área de uma cultura agrícola com alta exigência de água. Enquanto isso, no mesmo município há populações rurais e núcleos urbanos adjacentes que contam com precários sistemas de abastecimento de água.

Surge daí alguns questionamentos: Faz sentido produzir tamanha quantidade de banana, se na sua produção for utilizada mais água do que a extraída do território de maneira sustentável? Quais os benefícios sociais, ambientais e econômicos, que a região realmente tem a depender da exportação dos seus recursos hídricos através da Água Virtual? A água deve ser priorizada para o abastecimento humano, bem como para produzir alimentos para a população local ou para plantações para exportação?

A administração pública tem procurado por décadas resolver problemas de convivência (outrora combate) à estiagem, tendo recorrido à execução de projetos de transposição de bacias hidrográficas, não tão próximas como a do Rio São Francisco, onde se supõe que a água esteja em níveis de abundância, abundância essa que há muito vem sendo contestada, "a maior necessidade de águas para além-Araripe coincidiria com a estação seca dos meados do ano em que o Rio São Francisco permanecia com menor volume de água " (AB’SÁBER, 2006, p.8),

Nesse contexto, a presente pesquisa objetivou fornecer elementos para o efetivo estabelecimento de uma nova cultura da água, pautada em uma gestão ambientalmente responsável, 
socialmente justa e economicamente viável. E é nessa circunstância que se apresenta esse trabalho, inserido no processo de análise da sustentabilidade hídrica da bananicultura empresarial irrigada no Vale do Cariri cearense.

\section{TRANSPOSIÇÃO DE ÁGUA ÀS AVESSAS}

É incontestável que a água no semiárido brasileiro é a variável mais importante, sendo a disponibilidade desta, uma condição para uma plena e íntegra ocupação do território, e considerando que as extensas áreas atualmente ocupadas pela bananicultura empresarial irrigada no Vale do Cariri cearense consomem significativas quantidades de água e considerando que essa produção é majoritariamente escoada para fora da região, se faz necessário ponderar a (in) sustentabilidade desse sistema de produção agrícola, em face da não abundância do citado recurso.

O modelo pelo qual a bananicultura vem se desenvolvendo na região, objetiva principalmente o mercado consumidor externo, localizado nas grandes capitais do país, uma vez que apenas uma pequena parte fica no mercado regional. Por outro lado, a demanda interna de água na Região Metropolitana do Cariri (RMC) aumenta continuamente devido ao crescimento populacional. A segurança hídrica é algo imprescindível para sustentabilidade dos assentamos humanos, por conta disso é que a RMC foi contemplada com a transposição das águas do Rio São Francisco, por meio do seu prolongamento em território cearense, chamado de Cinturão das Águas do Ceará (CAC).

Assim, é no mínimo contraditório que uma região exporte um significativo volume de uma cultura agrícola altamente exigente em água, quando esta mesma região é constantemente acometida de secas prolongadas. Evidencia-se assim, um dos paradoxos do desenvolvimento da cadeia produtiva da bananicultura empresarial irrigada na região, uma vez que ocorre uma transposição de água às avessas, por meio da exportação de Água Virtual contida no processo produtivo da banana.

\section{ÁGUA VIRTUAL}

Quando uma região exporta um produto, também exporta por meio de um fluxo oculto a água necessária para produzi-lo. No intuito de facilitar o entendimento acerca desse invisível fluxo 
de água por meio de produtos, alguns pesquisadores se dedicaram a estudá-lo. Primeiramente foram levadas a cabo pesquisas pelo economista Gideon Fishelson em Israel na década de 80, seus estudos induziram o governo local a desestimular as consolidadas exportações de produtos agrícolas altamente exigentes em água, tradicionalmente cultivados mediante insustentáveis sistemas de irrigação, a exemplo da citricultura (cultivo de frutas do gênero Citrus, laranja, limão, tangerina, dentre outras).

À época Fishelson nomeou esse fluxo oculto de água como Valor Marginal da Água, e conclui que "ao custo de um encolhimento contínuo do setor agrícola, quantidade suficiente de água poderia ser salva para prover o crescimento da população" e ainda, "se no curto prazo não forem tomadas medidas para diminuir a demanda, testemunharemos um ano que o setor agrícola estará sob o risco de extinção" (FISHELSON, 1994). Vê-se ai que é imprescindível à avaliação por meio de indicadores o quanto uma cultura agrícola é ou não viável para uma região por quantidade de água que ela necessita.

$\mathrm{Na}$ década de 90 o geógrafo britânico Tony Allan cunhou o termo Água Virtual, este conceitualmente baseado nas pesquisas do israelita, enquanto Fishelson tinha como foco principal, as implicações de ordem econômica, as observações do britânico ficaram apenas no âmbito conceitualmente metafórico, não tendo muita inserção no campo prático da gestão (ALLAN, 2003), o mesmo autor ainda ensaiou anteriormente o uso do o termo Água Embutida, não havendo receptividade alguma.

Embora o termo Água Virtual tivera repercutido, não houve aplicação alguma até 2002, quando a Organização das Nações Unidas para Educação, Ciência e Cultura (UNESCO) realiza uma conferencia na cidade holandesa de Delf, tendo como tema central Água Virtual. Na ocasião, com o intuito de decodificar o conceito, aproximando-o da sociedade em geral, e dando um caráter operacional ao mesmo, o pesquisador holandês Arjen Hoekstra, propõe a Pegada Hídrica (HOEKSTRA, 2003), este indicador evidencia o consumo oculto de água contido nos produtos, sobretudo as commodities agrícolas.

\section{METODOLOGIA}


A área analisada encontra-se nos municípios de Barbalha e Missão Velha, localizados na Região Metropolitana do Cariri (Figura 1), microrregião do Vale do Cariri, sul do Estado do Ceará, região Nordeste do Brasil.

Os municípios situam-se no vale defronte a vertente norte da Chapada do Araripe, estandoos geograficamente assim localizados. Barbalha (Latitude: $-7^{\circ} 18^{\prime} 20^{\prime \prime}$ sul, Longitude: $-39^{\circ} 18^{\prime} 9^{\prime \prime}$ oeste e Altitude: 415 m), e Missão Velha (Latitude: -07²14'59" sul, Longitude: -3908'35" oeste e Altitude: $360 \mathrm{~m}$ ). A temperatura oscila entre $36^{\circ} \mathrm{C}$ a $19^{\circ} \mathrm{C}$ apresentando média de $27^{\circ} \mathrm{C}$.

FIGURA 1. LOCALIZAÇÃO GEOGRÁFICA DOS MUNICÍPIOS DE BARBALHA E MISSÃO VELHA.

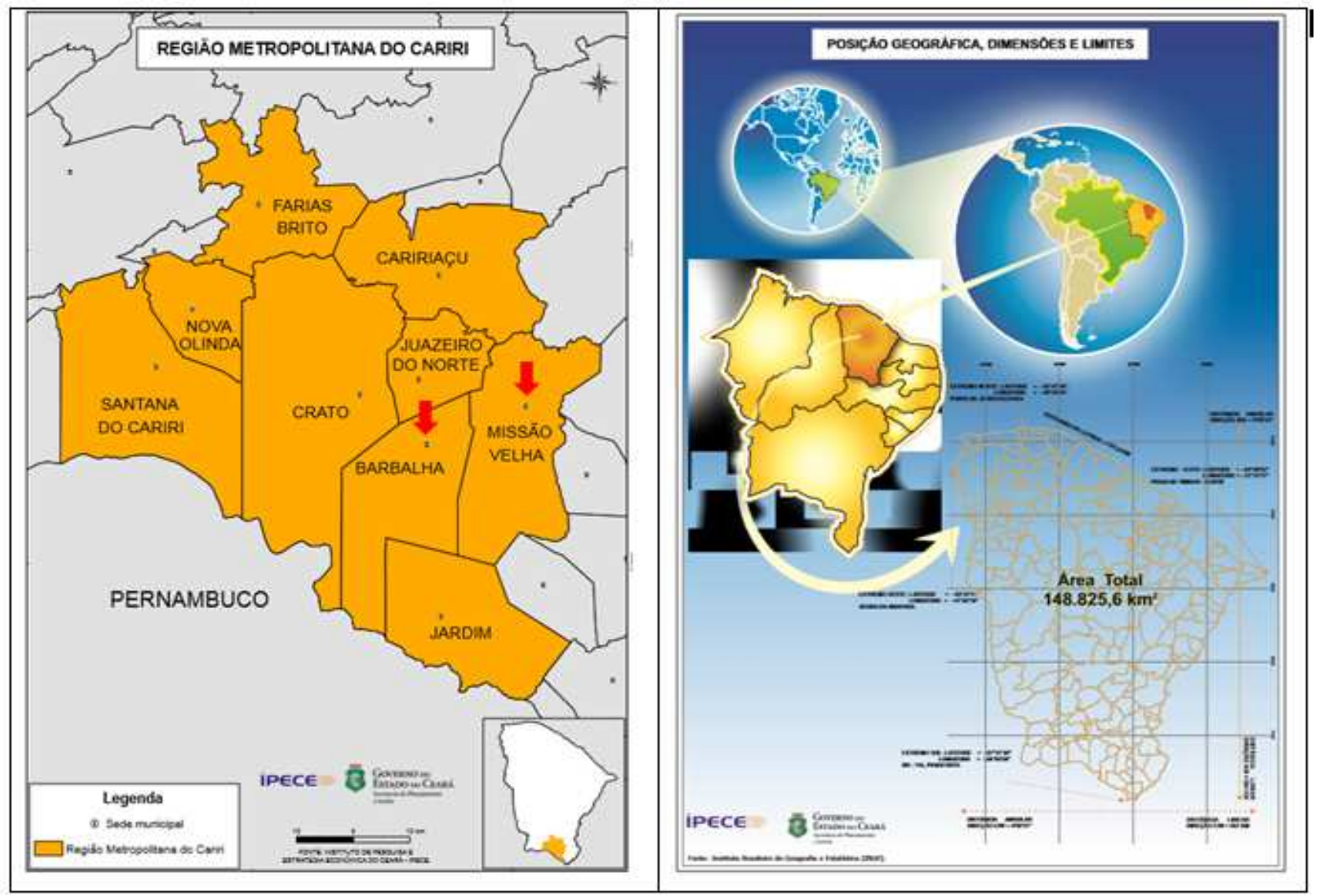

Fonte: Adaptado de IPECE, 2007.

Realizou-se a pesquisa por meio do uso de software de sensoriamento remoto, onde foram processadas e analisadas imagens multiespectrais obtidas em banco de dados de satélite espacial com alta resolução. Ao realizar o balanço de energia, foi possível quantificar a demanda de água nas áreas empresariais de bananicultura irrigada. 
A obtenção de imagens aéreas da área pesquisada ocorreu por meio do acesso ao banco de imagens do satélite Landsat 8 Sensor OLI TIRS órbita/ponto 217/65, disponível no portal virtual Earth Explorer do United States Geological Survey (USGS). Como base dos cálculos, foram obtidas as imagens mais recentes sem cobertura de nuvens entre as disponíveis, sendo as seguintes datas: 03 de março; 22 de maio; 09 de julho; 29 de outubro e 14 de novembro de 2016. Este ano foi escolhido porque foi um ano crítico referente à baixa disponibilidade hídrica após cinco anos consecutivos de seca. Estas imagens foram selecionadas, pois são de acesso livre e apresentam uma excelente percepção das condições de cobertura do solo nas áreas agrícolas empresariais cultivadas com banana de maneira irrigada.

Em seguida foi feito o empilhamento das bandas das imagens do Landsat 8, para fins de usar um algoritmo de saldo de radiação. As bandas utilizadas no empilhamento foram banda 2, 3, 4, 5, 6, 10, e 7, sendo possível identificar com bastante nitidez as áreas empresariais de cultivo de banana irrigada.

Para obtenção da taxa de evapotranspiração potencial de referência, nas áreas de cultivo irrigado, são necessários dados meteorológicos como: temperatura, velocidade do vento, temperatura do ponto de orvalho, pressão atmosférica, insolação, radiação, precipitação e outros utilizados nos processos de validação dos modelos e no cálculo da evapotranspiração de referência (ETo), através do software Ref ET-Reference Evapotranspiration Calculator (ALLEN, 2010). Os dados meteorológicos foram obtidos junto ao Instituto Nacional de Meteorologia (INMET), são oriundos da Estação Meteorológica de Barbalha No82784, Latitude: $-7.3^{\circ}$, Longitude: $-39.27^{\circ}$ e Altitude: $409,41 \mathrm{~m}$.

Em posse dos dados foi calculada a estimativa de ETo seguindo o método Penman-Monteith padrão FAO-56 (ALLEN et al. 1998). Com base em uma taxa hipotética de ETo para a cultura de grama com altura $12 \mathrm{~cm}$, e resistência aerodinâmica de $70 \mathrm{~s} \mathrm{~m}-1$. Essa é equação é expressa da seguinte forma:

$$
\mathrm{ET}_{0}=\frac{0.408 \Delta(\mathrm{Rn}-\mathrm{G})+\gamma \frac{900}{\mathrm{~T}+273} \mathrm{U}_{2}\left(\mathrm{e}_{\mathrm{s}}-\mathrm{e}_{\mathrm{a}}\right)}{\Delta+\gamma\left(1+0.34 \mathrm{U}_{2}\right)}
$$

Em que: ETo é a evapotranspiração da cultura de referência (mm d-1), Rn - radiação líquida na superfície da cultura (Mj.m-2.dia-1), G - fluxo de calor do solo (Mj.m-2.dia-1), T temperatura média do ar $\left({ }^{\circ} \mathrm{C}\right)$, U2 - velocidade do vento medida a $2 \mathrm{~m}$ de altura (m s-1), (es - ea) - déficit da 
pressão de vapor (Kpa), $\Delta$ representa a variação da declividade da curva da pressão de vapor (Kpa), $\gamma$ é a constante psicométrica ( $\left.\mathrm{Kpa}^{\circ} \mathrm{C}-1\right)$, e 900 um fator de conversão.

Para obtenção da evapotranspiração real das áreas cultivadas, segundo metodologia da FAO56 (Allen et al. 1998), a ETo é multiplicada pelo coeficiente de cultura - (Kc). Em vez de se usar os valores médios de Kc do manual da FAO-56 (Allen et al. 1998), optou-se neste trabalho, por se determinar esses Kc, como uma fração da evapotranspiração de 24 h, entre a evapotranspiração real e a ETo. Este Kc ou fração foi obtido em 5 momentos (imagens) ao longo do ano, para acompanhar as taxas de evapotranspiração real.

Para a obtenção do Kc da imagem de satélite utilizada, foi utilizado o algoritmo METRICMapping evapotranspiration at high resolution and with internalized calibration (ALLEN et al., 2010). Esse modelo possui várias etapas sequenciais para o cômputo da evapotranspiração com base nos elementos do balanço de energia na superfície. Em cada uma delas é realizado o cômputo de uma ou mais variáveis necessárias para as etapas seguintes.

Com o Kc, extraído a partir de imagens de satélites em várias datas, obteve-se o consumo mensal de água multiplicando a ETo mensal pelo Kc mais próximo do mês avaliado. Com os valores anuais de evapotranspiração foi computado consumo anual. Uma vez obtido o consumo anual, os valores que correspondem às áreas empresariais de bananicultura irrigada foram extraídos para se calcular a taxa média de consumo.

Para efeito de cálculo do Valor de Água Virtual (VAV) (HOEKSTRA, 2002) considera o volume de água evapotranspirada $\left(\mathrm{m}^{3}\right)$ no campo, dividida pela produção total. A relação dá-se em volume de água consumida por quantidade de vegetal produzida $(\mathrm{kg})$ e pode ser expressa em litro/quilograma $(\mathrm{L} / \mathrm{kg})$ ou metro cúbico/tonelada $\left(\mathrm{m}^{3} / \mathrm{ton}\right)$.

$$
\mathrm{VAV}=\frac{\mathrm{ETr}}{\text { Produção }}
$$

Para a obtenção da evapotranspiração real (ETr), foi utilizado a taxa gerada pelo METRIC, e para a produção foi usado dados do censo agropecuário do IBGE referente ao ano de 2016.

\section{RESULTADOS E DISCUSSÃO}


A partir das imagens analisadas foi possível quantificar a demanda de água nos cultivos empresariais de banana irrigada. O Kc médio não foi obtido da literatura como os que se encontram tabelados pela FAO-56 (ALLEN, et al., 1998), conforme observado em diversos trabalhos, mas utilizou-se um algoritmo de balanço de energia na obtenção de frações de evapotranspiração diretamente da área de estudo, equivalentes a um Kc real.

Considerando o consumo de água (ETr) da área de estudo para a imagem do mês de março, período chuvoso na região, verifica-se semelhança na coloração, entre as áreas de mata nativa, de outros cultivos e das áreas empresárias cultivada com banana irrigada, conforme Figura 2.

FIGURA 2. CONSUMO DE ÁGUA (EVAPOTRANSPIRAÇÃO REAL) NO MÊS DE MARÇO DE 2016.

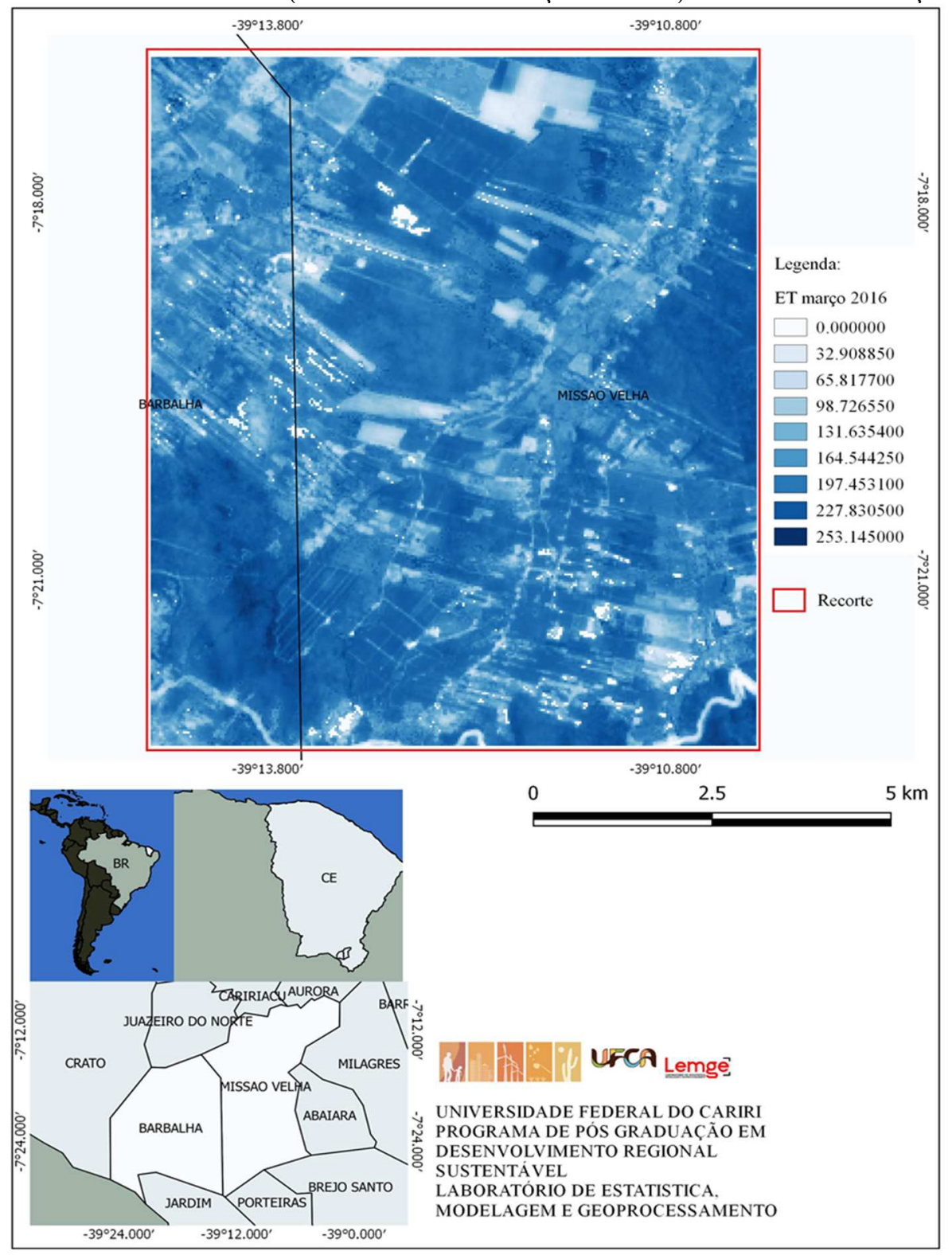

Fonte: Autores. 
De outra forma, quando se observa a imagem do mês de outubro (Figura 3), o consumo de água parece não existir nas áreas de mata nativa e de outros cultivos, enquanto as áreas empresariais cultivadas com banana irrigada se destacam com uma cor azul intensa. Apresentando ainda, pontos azuis mais intensos dentro das áreas cultivadas.

FIGURA 3. CONSUMO DE ÁGUA (EVAPOTRANSPIRAÇÃO REAL) NO MÊS DE OUTUBRO DE 2016.

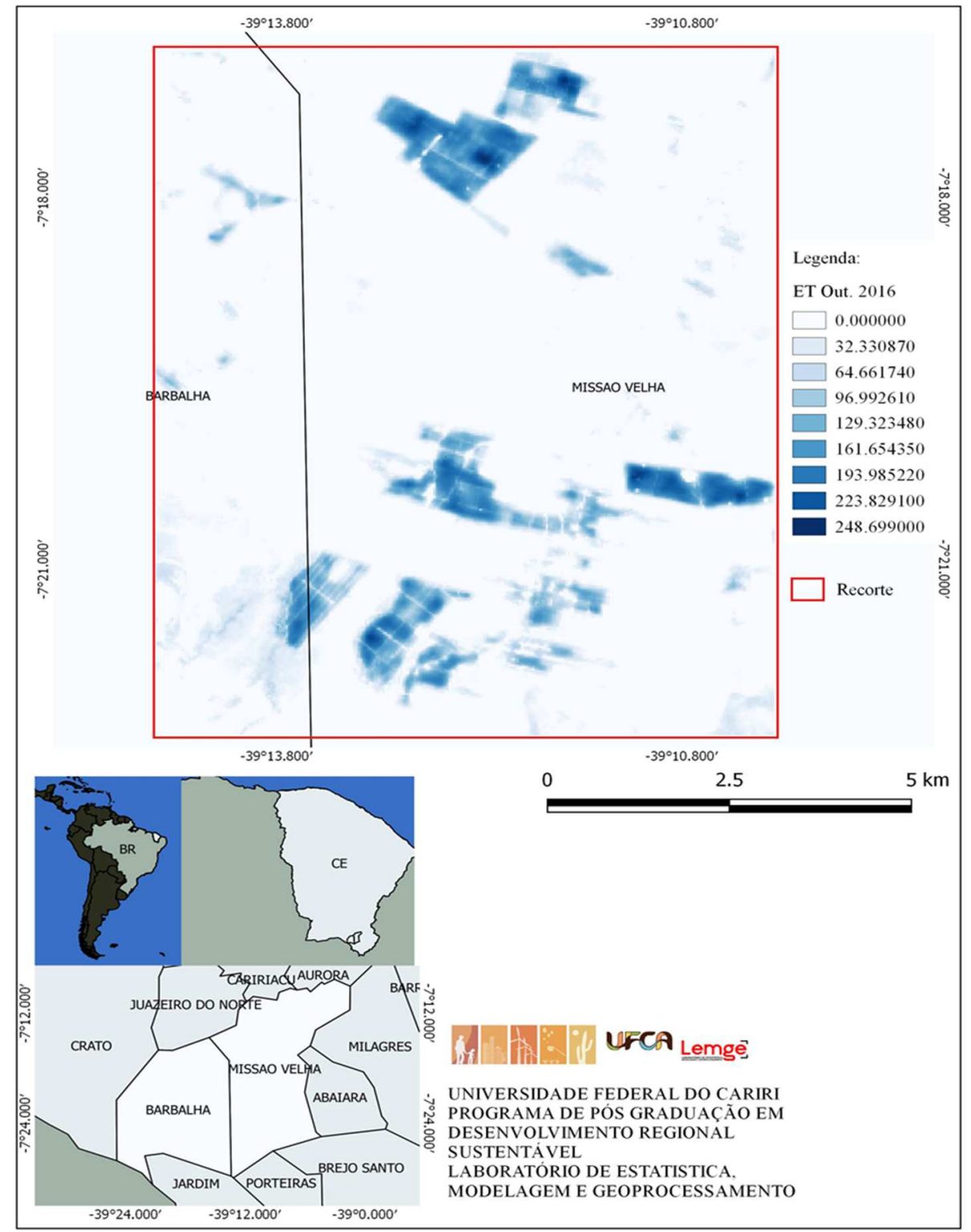

Fonte: Autores.

Na Figura 4 verifica-se que o consumo ocorre em toda a vegetação, mas em função da disponibilidade da água proveniente da irrigação, as áreas empresariais cultivadas com banana apresentaram consumo cerca de nove vezes maior que nas demais áreas. 
FIGURA 4. EVAPOTRANSPIRAÇÃO REAL ANUAL NO ANO DE 2016.

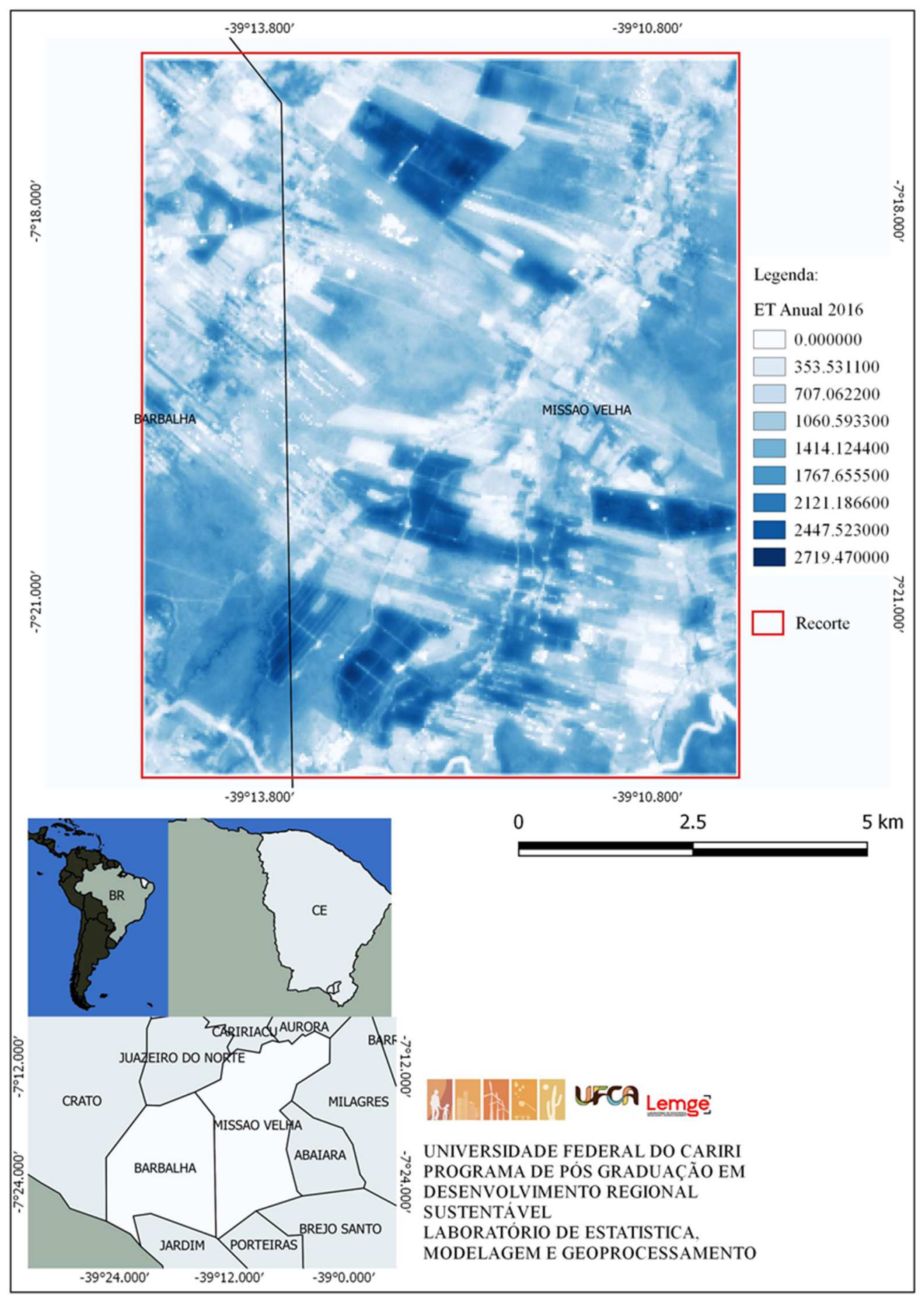

Fonte: Autores.

Observando somente as áreas empresariais irrigadas cultivadas com a banana (Figura 5), verifica-se um consumo significativo nestas áreas com relação às outras, e que realmente os maiores volumes de água são demandados das áreas onde é praticada a bananicultura empresarial irrigada. 
FIGURA 5. EVAPOTRANSPIRAÇÃO REAL NO ANO DE 2016 NAS ÁREAS EMPRESARIAIS COM BANANA IRRIGADAS.

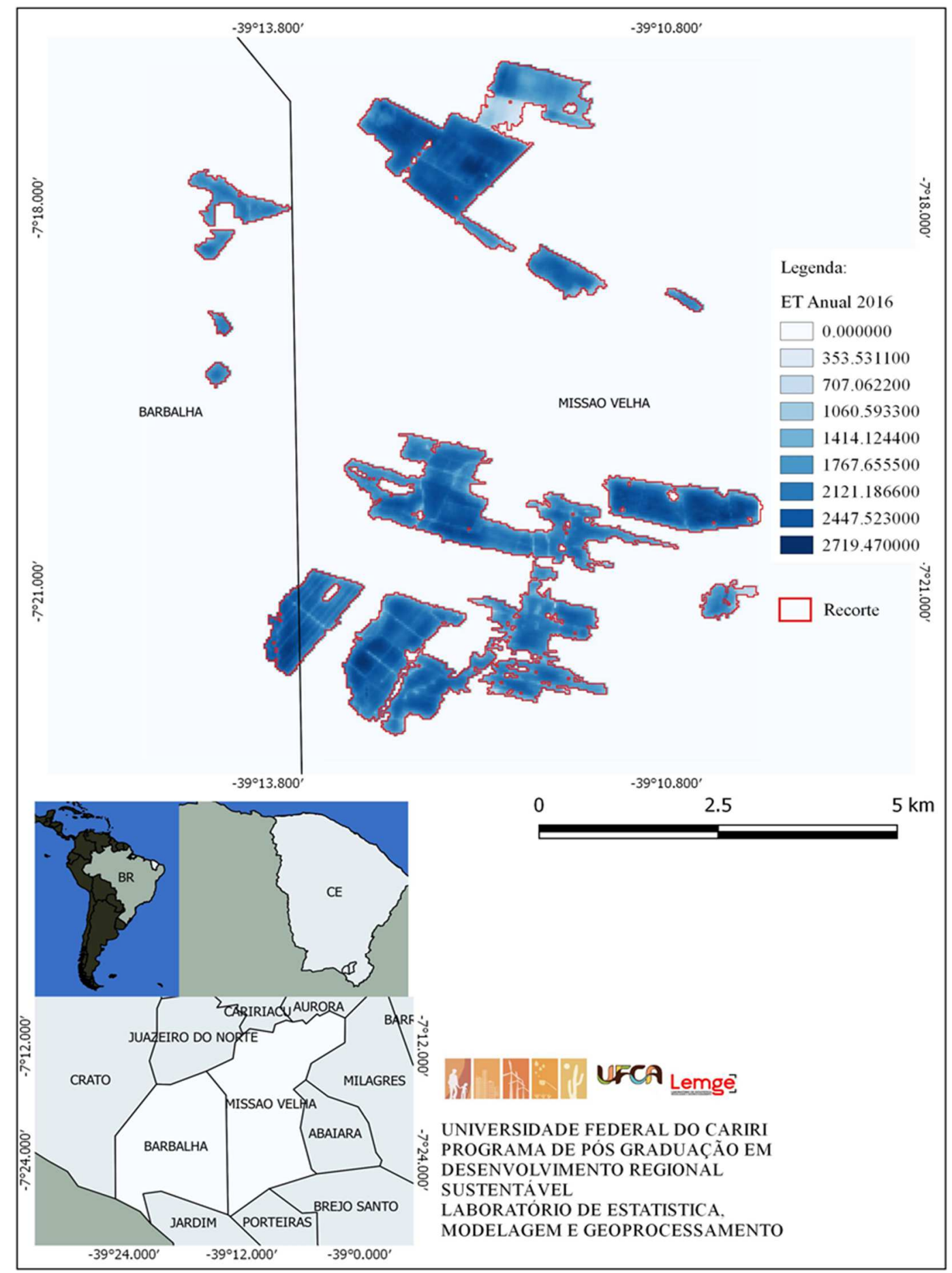

Fonte: Autores.

Conforme a Figura 5, nas áreas empresariais irrigadas o valor médio da ETr anual para 2016 é de 1880 mm, superior ao referendado pelo modelo FAO-56 (Allen et al., 1998), que é de $1700 \mathrm{~mm}$ (Tabela 1). 
TABELA 1. CONSUMO NAS ÁREAS EMPRESARIAIS IRRIGADAS (MM).

\begin{tabular}{|c|c|c|}
\hline Base de dados & Demanda mínima e máxima & Demanda média \\
\hline Obtidos na pesquisa & $1400-2719$ & 1880 \\
\hline FAO-56 (Allen et al., 1998) & $1200-2200$ & 1700 \\
\hline
\end{tabular}

Entretanto, olhando a imagem no inicio do ano, nota-se que trecho de uma área empresarial foi implantado ao longo do ano, e o consumo deste difere bastante das áreas em que a banana já alcançou seu pleno estágio de desenvolvimento, ao se descartar esta área, os valores médios podem ser vistos na Tabela 2 .

TABELA 2. CONSUMO NAS ÁREAS EMPRESARIAIS IRRIGADAS EM PLENO ESTÁGIO DE DESENVOLVIMENTO (MM).

\begin{tabular}{|c|c|c|}
\hline Base de dados & Demanda mínima e máxima & Demanda média \\
\hline Obtidos na pesquisa & $1700-2719$ & 2168 \\
\hline FAO-56 (Allen et al., 1998) & $1200-2200$ & 1700 \\
\hline
\end{tabular}

Fonte: Autores.

Um ponto importante que há de ser levado em consideração é que a recarga efetiva do aquífero onde estão localizadas as áreas empresariais irrigadas se encontra muito aquém do que é consumido pelas empresas do agronegócio da bananicultura, evidenciando um déficit da ordem de $2039 \mathrm{~mm}$ (Tabela 3).

TABELA 3. MÉDIA DE CONSUMO NAS ÁREAS EMPRESARIAIS IRRIGADAS / RECARGA ANUAL DO AQUÍFERO / DÉFICIT (MM).

\begin{tabular}{|c|c|c|c|}
\hline Base de dados & Recarga do aquífero & Consumo & Déficit \\
\hline Obtida na pesquisa & & 2168 & 2039 \\
\hline Barbalha e Missão Velha (COGERH, 2017) & 129 & & \\
\hline
\end{tabular}

Fonte: Autores.

O elevado consumo do recurso hídrico, além de promover prejuízos de ordem ambiental, econômico e social, pode evidenciar uma ineficiência também nos sistemas de irrigação, sem falar no estresse hídrico causado às plantas pelo excesso de água, gerando uma vulnerabilidade ao cultivo, sendo este facilmente atacado por pragas, induzido muitas vezes, ao uso irresponsável de agrotóxico por parte dos produtores, na perspectiva de se reduzir os potenciais prejuízos financeiros.

O montante de Água Virtual exportada (Figura 6) foi calculado com o uso do algoritmo METRIC, a partir do volume de água evapotranspirada (ETr), dividiu-se pelas 44.500 toneladas de banana produzidas no ano de 2016 (IBGE, 2018), chegando-se a média de $772 \mathrm{~L} / \mathrm{kg}$. 
FIGURA 6. ÁGUA VIRTUAL EXPORTADA NO ANO DE 2016 NAS ÁREAS EMPRESARIAIS COM BANANA IRRIGADAS.

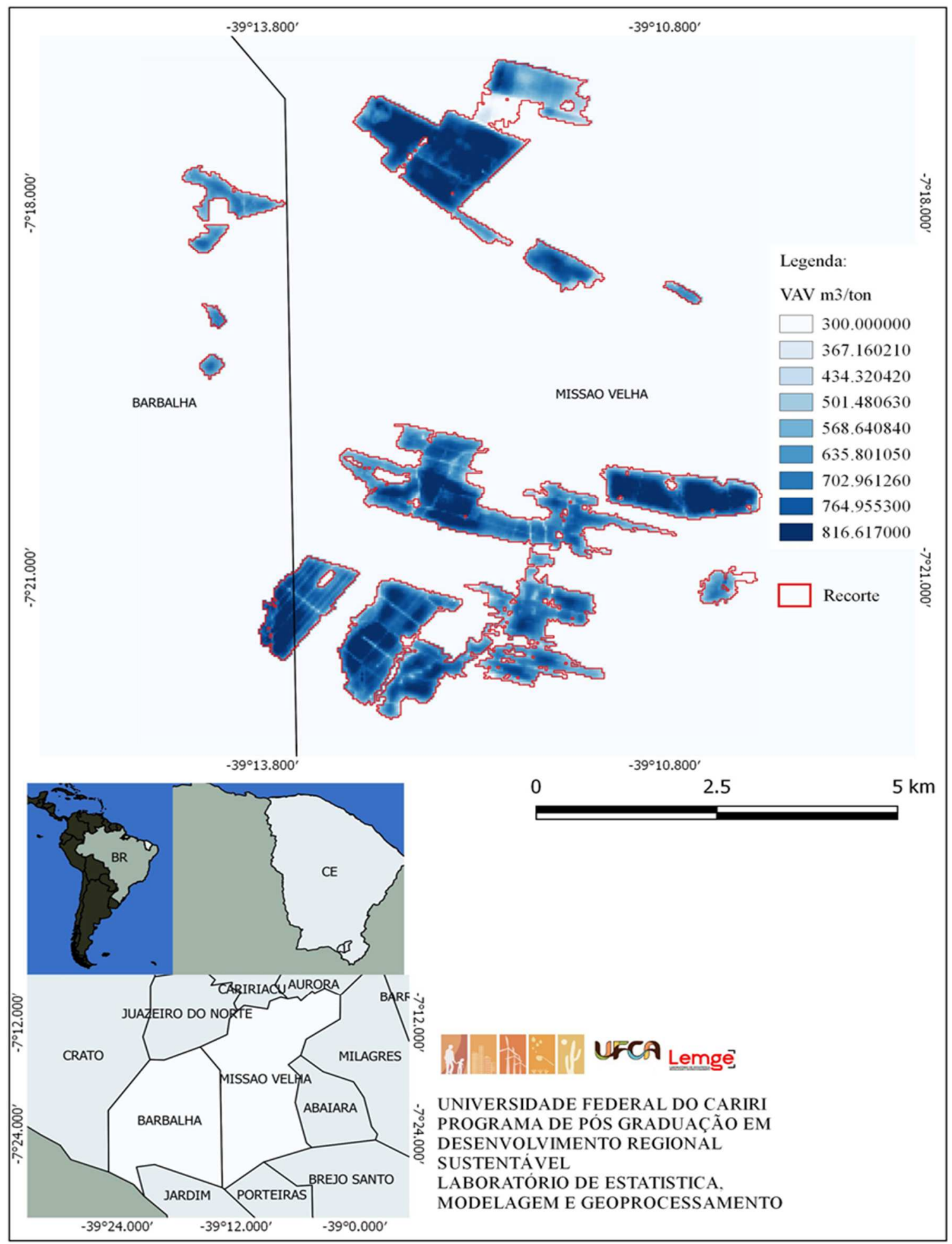

Fonte: Autores. 
Os resultados apontam que na região pesquisada, a relação de volume de água consumida por banana produzida $(\mathrm{L} / \mathrm{kg})$ está um pouco abaixo da média mundial, uma vez que foram contabilizados $772 \mathrm{~L} / \mathrm{kg}$, sendo a média mundial $790 \mathrm{~L} / \mathrm{kg}$ (MEKONNEN, HOESKSTRA, 2010). No entanto, quando calculado o volume total em metros cúbicos por tonelada $\left(\mathrm{m}^{3} / \mathrm{ton}\right)$, os valores são extremamente elevados (Quadro 1) para uma região contida em território semiárido.

QUADRO 1. RELAÇÃO DE ÁGUA CONSUMIDA POR BANANA PRODUZIDA NAS ÁREAS IRRIGADAS DOS MUNICÍPIOS DE BARBALHA E MISSÃO VELHA EM 2016.

\begin{tabular}{|l|l|}
\hline \multicolumn{1}{|c|}{ Água consumida } & \multicolumn{1}{|c|}{ Banana produzida } \\
\hline 772 litros & 1 quilograma \\
\hline 772.000 litros & 1000 quilogramas \\
\hline 34.354 .000 .000 (trinta e quatro bilhões trezentos e cinquenta e quatro milhões) litros & 44.500 toneladas \\
\hline 34.354 .000 (trinta e quatro milhões trezentos e cinquenta e quatro mil) metros cúbicos & 44.500 toneladas \\
\hline
\end{tabular}
Fonte: Autores.

A quantidade de Água Virtual exportada é igual ao consumo efetivo, uma vez que a produção das áreas empresariais irrigadas visa o mercado externo. Tendo por referência a Operação Carro-Pipa do Governo Federal (BRASIL, 2012) onde são transportados 10 mil litros de água por veículo, esse volume corresponde a 3.435 .400 (três milhões quatrocentos e trinta e cinco mil e quatrocentos) carros-pipa que deixaram o território semiárido no ano de 2016, configurando-se uma verdadeira transposição de água às avessas.

De posse dos dados expostos no Quadro 1 e dos volumes outorgados pela Companhia de Gestão de Recursos Hídricos (COGERH), obteve-se o volume real (Tabela 4) consumido nas áreas irrigadas dos municípios de Barbalha e Missão Velha, volume esse incongruente com o legalmente outorgado para atividades de irrigação nos referidos municípios (COGERH, 2017).

TABELA 4. RELAÇÃO DE CONSUMO EFETIVO DE ÁGUA NAS ÁREAS IRRIGADAS DOS MUNICÍPIOS DE BARBALHA E MISSÃO VELHA E VOLUME OUTORGADO (METROS CÚBICOS).

\begin{tabular}{|c|c|c|}
\hline Consumo efetivo obtida na pesquisa & Outorgado (COGERH, 2017) & Exploração ilegal \\
\hline 34.354 .000 & 5.578 .897 & 28.775 .103 \\
\hline
\end{tabular}

$$
\text { Fonte: Autores. }
$$

Os dados expostos na Tabela 4 evidenciam que a quantidade de água efetivamente consumida em atividades de irrigação nos municípios de Barbalha e Missão Velha, é muito superior ao volume outorgado (licenciado) pela COGERH (2017). O volume explorado excessivamente de maneira ilegal, sugere medidas de fiscalização efetiva por parte dos órgãos de controle, uma vez que a não adoção destas, podem acarretar em insegurança hídrica para a toda a população da Região Metropolitana do Cariri. Não resta dúvida de que a questão que envolve a gestão dos recursos 
hídricos, além de social e ambiental, é econômica. No entanto, sendo a água um bem público, o setor econômico não deve ser determinante.

$\mathrm{Na}$ Figura 7, têm-se os principais destinos da exportação de Água Virtual proveniente da bananicultura comercial irrigada.

FIGURA 7. FLUXO DE ÁGUA VIRTUAL EXPORTADA A PARTIR DO VALE DO CARIRI CEARENSE.

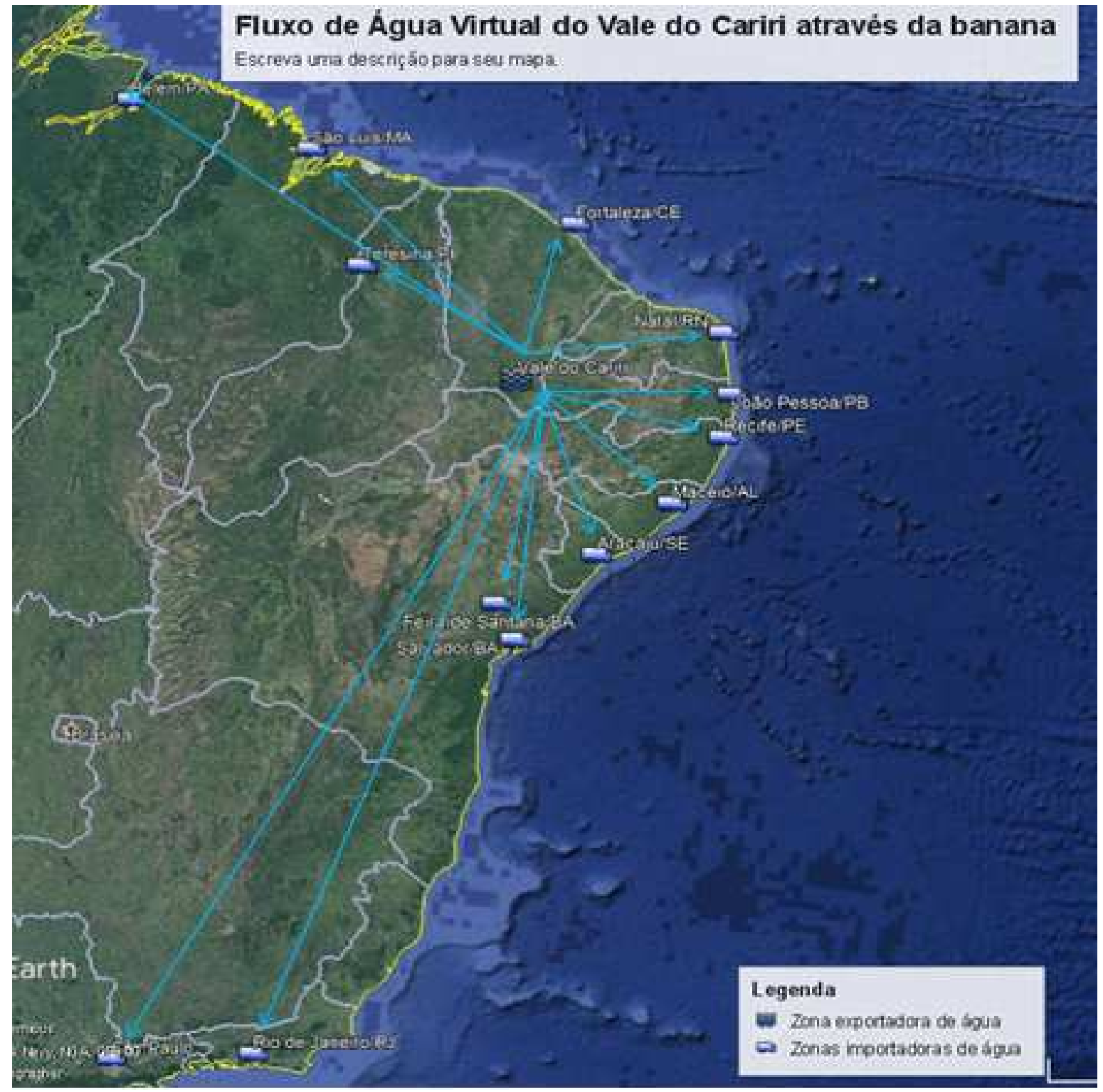

Fonte: Autores, adaptado de Google (2019).

Diante do exposto, percebe-se que a gestão sustentável das águas é uma questão complexa, e para que se torne efetiva, necessita de uma mudança paradigmática estrutural no intuito de uma gestão socialmente justa. Assim, a gestão pública (municipal/estadual/federal) frente ameaça de 
uma escassez generalizada de água, considerando que os recursos hídricos são finitos, sendo limitados e frágeis, não deve descartar dentro do conjunto de ações que precisam ser implantadas, o estabelecimento de embargos a determinadas culturas agrícolas altamente exigentes em água, a exemplo da banana.

\section{CONSIDERAÇÕES FINAIS}

Mensurando a Água Virtual, verificou-se que a relação de água consumida por quilograma produzido $(\mathrm{L} / \mathrm{kg})$ de banana na região mostrou-se um pouco abaixo da média mundial, uma vez que foram encontrados os valores de $772 \mathrm{~L} / \mathrm{kg}$, sendo a média mundial $790 \mathrm{~L} / \mathrm{kg}$. Essa água segue como Água Virtual, através da banana, para abastecer, em grande parte, outros centros. Enquanto a média de consumo de água no restante do mundo pela bananeira em seu pleno estágio de desenvolvimento em áreas irrigadas é de $1700 \mathrm{~mm}$, para a região de estudo são $2168 \mathrm{~mm}$.

Também foi mapeado o fluxo de Água Virtual que parte do Vale do Cariri cearense em forma de banana, sendo identificado como destino, centros consumidores das zonas urbanas das regiões Norte (Belém/PA), Nordeste (Aracaju/SE, Feira de Santana/BA, Fortaleza/CE, João Pessoa/PB, Maceió/AL, Natal/RN, Recife//PE, São Luiz/MA, Salvador/BA e Teresina/PI) e Sudeste (São Paulo/SP e Rio de Janeiro/RJ).

Conclui-se ainda que, é importante o conhecimento do real volume de água consumido por parte das culturas agrícolas a partir de dados locais, uma vez que a partir destes se permite uma aplicação racional do recurso tendo por base o potencial hídrico da região. Uma vez que o Vale do Cariri cearense é extremamente dependente de águas subterrâneas, o que torna essencial a aplicação de mecanismos de monitoramento e controle dos usos dos aquíferos, evitando um potencial colapso de abastecimento no futuro, ou em circunstâncias de severas estiagens.

A pesquisa teve como foco principal inserir um olhar crítico sobre um modelo de produção agrícola ainda visto com certa superficialidade por uma significativa parcela da sociedade. No entanto, faz-se necessário que outros olhares, sob outras perspectivas, sejam lançados no intuito de avançar nesse processo coletivo de reflexão e proposição, acerca de uma gestão responsável de um elemento de caráter multidimensional que é a água, cuja sua disponibilidade de forma íntegra em qualidade e quantidade é imprescindível para que ninguém seja privado de seu acesso, havendo assim justiça social. 
Para uma melhor aferição e analise integral quanto à sustentabilidade desse modelo de agricultura, é necessária a realização de estudos que abordem outras dimensões da sustentabilidade sob um aspecto holístico. É preciso investigar esse sistema para além do marketing daqueles que dele se beneficiam. A (eco) lógica da sustentabilidade sucinta uma incongruência da agricultura empresarial irrigada para exportação realizada em uma região semiárida, uma vez que é utilizado um expressivo volume de água para produzir para o mercado externo, enquanto parte da população local não é provida de água para satisfazer as mais básicas necessidades.

Tais fatos deixam claro que se deve induzir a escolha política para restringir a produção para exportação de alimentos, que para além de altamente exigentes em água, ainda promovem contaminação do solo, dos mananciais e geram inúmeras enfermidades. Faz-se necessário que as instancias reguladoras, dentre as quais autarquias públicas, comitês de bacia e conselhos temáticos, ponderem a insustentabilidade de determinados sistemas de produção agrícola que não coadunam com a manutenção da vida. Nesse sentido, uma possível chave para um processo de gestão social dos recursos hídricos do território, está associada à instauração de mecanismos jurídicos de controle social, a exemplo de audiências públicas para que seja examinada a sustentabilidade do uso, quando da solicitação da outorga de uso de água, por parte de empreendimentos destinados a agricultura para exportação.

Para encerrar, mas sem fechar a questão, torna-se imprescindível avançar nas reflexões acerca de segurança hídrica e alimentar, pautada em uma visão que transcenda o aspecto regional, não pelo organizado mercado globalizado, mas sim por questões obvias que perpassam uma mudança de paradigmas em função de uma integral sustentabilidade ambiental e, por conseguinte, das próprias populações que com este interagem.

\section{REFERÊNCIAS}

AB'SÁBER, A.N. A transposição de águas do São Francisco: análise crítica. São Paulo: Revista USP, (70), pp. 6-13, 2006.

ALLAN, J.A. Virtual Water: The Water, Food, and Trade Nexus Useful Concept or Misleading Metaphor? Water International, Volume 28, N 1, March, pp. 4-11, 2003.

ALLEN, R.G. Ref-ET: Reference Evapotranspiration Calculation Software. Kimberly: University of Idaho, 2002.

ALLEN, R.G.; TASUMI, M.; TREZZA, R. Mapping evapotranspiration at high resolution, application manual for Landsat satellite imagery. Kimberly: University of Idaho, 2010. 
ALLEN, R.G.; PEREIRA, L. S.; RAES, D.; SMITH, M. Crop evapotranspiration: Guide lines for computing crop water requirements. (Irrigation and Drainage Paper - 56). Rome: FAO, 1998.

BRASIL. Portaria Interministerial No 1/MI/MD, de 25 de julho de 2012 - Dispõe sobre a realização da Operação Carro-Pipa. Brasília: Governo Federal, 2012.

CEARÁ. Declaração de Emergência: série histórica de registros. Fortaleza: Coordenadoria Estadual de Defesa Civil do Ceará, 2019.

COGERH. Estudos das Águas Subterrâneas da Bacia do Araripe (Relatório Síntese dos Estudos Qualitativos e Quantitativos). Fortaleza: COGERH/IPECE/SRH, 2017.

FISHELSON, G. The Allocation and Marginal Value Product of Water In Israeli Agriculture. pp. 427- 440. In: ISSAC, J.; SHUVAL, H. (Ed.) Water and Peace in the Middle East. $1^{\circ} \mathrm{Ed}$, Studies in Environmental Science, 528p. 1994.

GOOGLE. Google Earth Pro. Disponível em: < https://www.google.com.br/earth/ > Acesso em: $31 / 01 / 2019$.

HOEKSTRA, A.Y. Virtual Water Trade: Proceedings of the international expert meeting on virtual water trade. Delft: Value of water research report series, n.12. UNESCO / Institute for Water Education, 2003.

HOEKSTRA, A.Y; HUNG, P.Q. Virtual Water Trade: A Quantification of Virtual Water Flows between nations in relation to international crop trade. Delf: Value of water research report series $\mathrm{n}$. 11, UNESCO / Institute for Water Education, 2002.

IBGE. Missão Velha/CE: Produção Agrícola - Lavoura Permanente (2019). Instituto Brasileiro de Geografia e Estatística. Disponível em: < https://cidades.ibge.gov.br/brasil/ce/missaovelha/panorama $>$ Acesso em: 22/02/2021.

INMET. Banco de Dados Meteorológicos para Ensino e Pesquisa. Instituto Nacional de Meteorologia. Disponível em: < http://www.inmet.gov.br > Acesso em: 20/12/ 2018.

IPECE. Ceará em Mapas. Fortaleza: Instituto de Pesquisa e Estratégia Econômica do Ceará. 2007.

MEKONNEN, M.M. e HOEKSTRA, A. Y. The Grenn, Blue and Grey Water Footprint of Crops and Derived Crop Products: (Volume 1). Delf: Main Report. UNESCO / Institute for Water Education, 2010.

ONU. World Urbanization Prospects. New York: United Natios / Population Division, 2018. Disponível em: < https://population.un.org/wup/ > Acesso em: 22/02/2021.

USGS. LANDSAT 8 OLI/TIRS (imagens). United States Geological Survey. Disponível em: < https://earthexplorer.usgs.gov > Acesso em: 20/12/ 2018. 